\title{
Effect of dry probiotic supplemented fermented feed on production performance of Akar Putra chicken
}

\begin{abstract}
During the recent years, solid state fermented feed (SSFF) has been introduced with great success in poultry nutrition. Thus, the present experiment was conducted to evaluate the effect of dry fermented feed with prepared probiotic (PP) on the live body weight, weight gain, feed intake and feed conversion ratio of a local Malaysian chicken (Akar Putra). The experiment comprised of 3 treatments ( 24 chicken/treatment), with 3 replicates of each (8 chicken/replicate). The treatments consisted of a control group (T1), the mixture of SSFF and $\mathrm{PP}$ at the rate 1:1:1 (1 kg of commercial broiler feed +1 liter tap water+1 $\mathrm{g}$ PP) in T2 and 1:1:2 (1 kg of commercial broiler feed +1 liter tap water+2 $\mathrm{g} \mathrm{PP}$ ) in T3. The results revealed remarkably significant $(\mathrm{p}<0.01)$ improvement in both male and female chicken in terms of final body weight gain, feed intake and feed conversion ratio in treatment groups (T2 and T3) when compared to the control group. The variation ratio of production performance parameters was calculated and best results were indicated in T2 group wherein, $1 \mathrm{~g}$ prepared probiotic was used.
\end{abstract}

Keyword: Akar putra chicken; Fermented feed; Probiotic 